E-JURNAL EKONOMI DAN BISNIS UNIVERSITAS UDAYANA
Available online at https://ojs.unud.ac.id/index.php/EEB/index
Vol. 10 No. 8, August 2021, pages: 709-720
e-ISSN: 2337-3067

\title{
MEMOTRET KEBERHASILAN SIMRS TERHADAP KUALITAS PELAYANAN SELAMA PANDEMI COVID-19 DI RUMAH SAKIT SWASTA DI BALI
}

\section{Ni Luh Komang Try Widyantari ${ }^{1}$ Ida Bagus Teddy Prianthara ${ }^{2}$}

\begin{tabular}{l}
\hline \multicolumn{1}{c}{ Article history: } \\
\hline Submitted: 7 Mei 2021 \\
Revised: 9 Juni 2021 \\
Accepted: 30 Juni 2021 \\
\hline
\end{tabular}

\section{Keywords:}

Hospital Information System; Healthcare Quality (HIS); Private Hospital; Covid-19;

\begin{abstract}
This study aims to capture HIS achievement on the quality of service during the Covid-19 pandemic in private hospitals in Bali. This research has been conducted at a private hospital in Bali that has and implements HIS, by giving questionnaires to 100 respondents. The research data were analysed using the SEM (Structural Equation Model) method using SmartPLS 3.3. The results of this study were Safety Quality, System Quality, and Information Quality from the HIS proved to have a positive and significant effect on the quality of health services during the Covid-19 pandemic in private hospitals in Bali ( $t$-statistic > 1,96 and p-value <0,05). Service Quality from HIS has not been proven to have a positive and significant effect on the quality of health services during the Covid-19 pandemic in private hospitals in Bali ( $t$-statistic < 1,96 and p-value >0,05). The quality system of the HIS is the most dominant factor affecting the quality of health services which has a path coefficient of 0.526.
\end{abstract}

\section{Kata Kunci:}

Sistem Informasi Manajemen Rumah Sakit (SIMRS);

Kualitas Pelayanan Kesehatan; Rumah Sakit Swastwa; Covid-19;

\section{Koresponding:}

Universitas Pendidikan

Nasional, Bali, Indonesia

Email:

trywidyantari@gmail.com

\begin{tabular}{l} 
Abstrak \\
\hline Penelitian ini bertujuan untuk memotret keberhasilan SIMRS \\
terhadap kualitas pelayanan selama Pandemi Covid-19 di Rumah Sakit \\
Swasta di Bali. Penelitian ini telah dilakukan di Rumah Sakit Swasta di Bali \\
yang memiliki dan menerapkan SIMRS dengan memberikan kuisioner \\
kepada 100 responden. Data penelitian dianalisis dengan metode SEM \\
(Structural Equation Model) menggunakan SmartPLS 3.3. Hasil penelitian \\
ini adalah Safety Quality, System Quality, dan Information Quality dari \\
SIMRS terbukti berpengaruh positif dan signifikan terhadap kualitas \\
pelayanan Kesehatan selama pandemi covid-19 di RS Swasta di Bali (t- \\
statistic > 1,96 dan p value < 0,05). Service Quality dari SIMRS tidak \\
terbukti berpengaruh positif dan signifikan terhadap kualitas pelayanan \\
kesehatan selama pandemi covid-19 di RS Swasta di Bali (t-statistic < 1,96 \\
dan $p$ value > 0,05). System Quality dari SIMRS merupakan faktor yang \\
paling dominan yang mempengaruhi kualitas pelayanan Kesehatan yang \\
memiliki koefisien path 0,526.
\end{tabular}

Universitas Pendidikan Nasional, Bali, Indonesia ${ }^{2}$

Email: teddy.akuntan@yahoo.com² 


\section{PENDAHULUAN}

Kesehatan menjadi salah satu masalah utama di dunia sebagaimana tercantum dalam Sustainable Development Goals (SDGs) pada tahun 2015 hingga 2030 (United Nations, 2020). Untuk mendukung SDGs, dukungan layanan optimal dari semua pihak dan pemangku kepentingan yang terlibat dalam lembaga pemerintah dan swasta sangat dibutuhkan (Handayani dkk., 2017). Kementerian Kesehatan Republik Indonesia telah meluncurkan program yang disebut $e$ Health sebagai bagian dari implementasi UU No. 14, disahkan pada 2008, mengenai Informasi Publik dan Peraturan Menteri Kesehatan Republik Indonesia Nomor 1691/ Menkes/ Per/ VIII/2011 tentang Keselamatan Pasien Rumah Sakit (Peraturan Menteri Kesehatan RI No 1691/Menkes/PER/VIII/2011, 2011). Pemerintah Indonesia sudah membagikan kebijakan buat mengharuskan rumah sakit buat menyelenggarakan SIMRS dalam Undang- Undang No 44 Tahun 2009 tentang Rumah Sakit pada pasal 52 ayat (1) kalau tiap Rumah Sakit harus melaksanakan pencatatan serta pelaporan tentang seluruh aktivitas penyelenggaraan Rumah Sakit dalam wujud Sistem Informasi Manajemen Rumah Sakit (SIMRS). Pelaporan tersebut diintegrasikan dengan dashboard Kemenkes yang bertujuan buat menjamin ketersediaan, mutu serta akses informasi kesehatan prioritas serta muatan informasi yang lain dan memaksimalkan aliran informasi kesehatan dari kabupaten/ kota serta/ ataupun provinsi ke Departemen ataupun kebalikannya (Odelia, 2018).

SIMRS ialah sesuatu sistem terkomputerisasi yang sanggup melaksanakan pengolahan informasi secara kilat, akurat, serta menciptakan sekumpulan data yang silih berhubungan buat diberikan kepada seluruh tingkatan manajemen di rumah sakit (Saputra, 2013). SIMRS ini bermanfaat mendukung proses fungsi- fungsi manajemen serta pengambilan keputusan dalam membagikan pelayanan kesehatan di rumah sakit (Aji, 2017). Tujuan berarti lain dari SIMRS merupakan pertukaran informasi elektronik antar penyedia layanan kesehatan( dokter aplikasi, sarana primer serta rumah sakit) sehingga bisa menjamin ketersediaan data penderita secara komprehensif serta efisiensi pelayanan (Nugroho, 2013). SIMRS yang digunakan di suatu rumah sakit wajib membagikan kemudahan dalam operasional dan wajib bisa menanggulangi hambatan pelayanan penderita yang terdapat di rumah sakit tersebut (Gunawan, 2013). Standar Nasional Akreditasi Rumah Sakit (SNARS) mengharuskan penyelenggaraan sistem data manajemen rumah sakit (SIMRS) wajib mengacu peraturan perundang- undangan. Rumah sakit menetapkan unit kerja yang mengelola SIMRS serta mempunyai sumber energi manusia yang terdiri atas kepala unit dan staf dengan kualifikasi analisis sistem, programmer, hardware, serta pemeliharaan jaringan (Komisi Akreditasi Rumah Sakit, 2018).

Aplikasi SIMRS ialah salah satu wujud investasi rumah sakit. Banyakrumah sakit berinvestasi dalam SIMRS sebab banyak manfaat yang diperoleh. Manfaat- manfaat tersebut bisa berbentuk manfaat secara universal, manfaat operasional, manfaat manajerial, sampai manfaat organisasi. Buat membenarkan kalau sesuatu sistem bisa penuhi sasaran manfaat yang diharapkan baik untuk karyawan orang ataupun untuk organisasi, hingga dibutuhkan penilaian serta evaluasi atas mutu sesuatu sistem data. Oleh sebab itu dibutuhkan tata cara buat melaksanakan penilaian mutu SIMRS. Dengan terdapatnya tata cara pengukuran mutu selaku wujud penilaian sistem, hingga hendak didapatkan parameter yang pas buat memperhitungkan kesuksesan sistem. Sehingga dari hasil penilaian serta evaluasi mutu SIMRS tersebut hendak digunakan selaku feedback untuk organisasi serta pengembangan sistem selanjutnya (Hariningsih, 2014).

Kualitas sistem informasi yang digunakan dalam sesuatu rumah sakit, berkaitan dengan sistem data yang diterapkan cocok dengan kebutuhan serta keahlian user sehingga bisa bekerjasama buat mencerna informasi jadi sesuatu data yang bermutu serta bermanfaat untuk pemakai data tersebut (Amalia \& Pratomo, 2016). Semakin tinggi kualitas informasi yang dihasilkan suatu SIMRS, akan 
semakin meningkatkan kepuasan pemakai. Kualitas dari SIMRS meliputi Safety Quality, System Quality, Information Quality, dan Service Quality (Falsteen, 2016). Amalia dan Pratomo (2016), melakukan riset mengenai kualitas sistem informasi, kualitas informasi, dan perceived usefulness terhadap kepuasan pengguna sistem informasi. Hasil dari penelitian tersebut adalah kualitas sistem informasi, kualitas informasi, dan perceived usefulness berpengaruh signifikan terhadap kepuasan pengguna sistem informasi.

SIMRS dianggap sebagai bagian penting dari sistem pelayanan kesehatan di rumah sakit. Pemanfaatan SIMRS meningkatkan efektivitas dengan mengurangi waktu dan meningkatkan kualitas pelayanan kesehatan di rumah sakit. SIMRS merampingkan proses kompleks di Rumah Sakit sehingga dapat memberikan pelayanan kesehatan yang lebih baik untuk pasiennya (Erlirianto dkk., 2015). Kualitas pelayanan kesehatan (Service Quality) meliputi 5 aspek yaitu Tangibles, Reliability, Responsiveness, Assurance dan Emphaty (Parasuraman et al., 2011). Saat ini Rumah Sakit dituntut untuk selalu meningkatkan pelayanan kesehatan kepada masyarakat berupa peningkatan akreditasi (tipe) rumah sakit. Tetapi penerapan Sistem informasi manajemen rumah sakit, banyak mengalami kegagalan dan ada juga yang bisa dikatakan berhasil (Mardiyoko \& Hartini, 2018)

Di masa Pandemi Coronavirus Disease (COVID-19) yang terjadi di tahun 2020 ini merupakan kejadian luar biasa yang membutuhkan pelayanan Kesehatan yang lebih optimal. COVID19 adalah virus jenis baru yang belum pernah diidentifikasi sebelumnya pada manusia (Susilo et al., 2020). Tanggal 30 Januari 2020 WHO telah menetapkan sebagai Public Health Emergency of International Concern (PHEIC). WHO melaporkan bahwa penularan dari manusia ke manusia terbatas (pada kontak erat dan petugas kesehatan) telah dikonfirmasi di China maupun negara lain. Penularan manusia ke manusia terjadi melalui droplet, kontak dan benda yang terkontaminasi (Kementerian Kesehatan Republik Indonesia, 2020). Untuk mencegah atau membatasi penularan infeksi di sarana pelayanan kesehatan memerlukan penerapan prosedur dan protokol Kesehatan (Lam et al., 2015). Adanya sistem informasi di rumah sakit saat ini dapat mempercepat pelayanan pada pasien sehingga akan mengurangi interaksi atau kontak antar manusia baik antara pasien, masyarakat dan tenaga Kesehatan.

Hasil riset Lestari (2014) terkait Evaluasi Sistem Informasi Manajemen Rumah Sakit di Rumah Sakit Rajawali Citra Bantul Yogyakarta, dengan kinerja sistem informasi, dapat mempercapat pelayanan pasien dalam hal ini proses mendaftarkan pasien dan pencarian data. Informasi yang dihasilkan lengkap dan tepat waktu. Namun Informasi yang dihasilkan keakuratannya masih perlu diperiksa kembali sehingga petugas masih mengecek kebenaran laporan. Hal ini menambah beban dalam kinerja petugas sehingga petugas tidak puas dengan adanya SIM di RS Rajawali

Hasil riset lainnya yaitu Setyaningrum (2015), dalam analisis sistem informasi registrasi pasien di RS Mulia Hati Wonogiti, hasil yang ditemukan pada analisis kinerja sistem informasi pada registrasi pasien kurang optimal, hal ini karena dalam pencarian rekam medik masih manual dan kurang efisien. Sistem informasi pada registrasi pasien tersedia namun sering terjadi data eror secara otomatis sehingga dapat input data dilakukan manual. Petugas belum puas dengan adanya sistem informasi pada registrasi pasien karena beban kinerja petugas registrasi bertambah, dan beresiko terjadi kesalahan dalam input data pasien.

Bali merupakan salah satu daerah tujuan wisata di dunia ikut mensukseskan pembangunan nasional dengan jalan melaksanakan pembangunan di segala bidang baik bersifat fisik maupun non fisik, seperti bidang pariwisata, perekonomian, perumahan, Pendidikan, sosial budaya dan kesehatan. Pelaksanaan pelayanan kesehatan yang integartif dan komprehensif, dilakukan di Rumah Sakit, dimana rumah sakit berperan sebagai suatu kebutuhan primer masyarakat, yaitu harus tersedianya fasilitas yang cukup baik secara kualitas dan kuantitas. Terjadi peningkatan jumlah RS dan klinik

Memotret Keberhasilan SIMRS Terhadap Kualitas Pelayanan Selama Pandemi Covid-19 di Rumah Sakit Swasta 
swasta juga terjadi di Provinsi Bali khususnya Kota Denpasar. Hingga akhir tahun 2017 di Kota Denpasar tercatat ada 2 RS milik pemerintah, 14 RS swasta, 1 RS khusus dan 2 RS kepolisian dan tantara (Dinas Kesehatan Provinsi Bali, 2017). Rumah Sakit Swasta di Bali khususnya Denpasar yang telah menerapkan SIMRS adalah RSU Kasih Ibu Denpasar, RSU Surya Husadha, RSU Prima Medika, RSU Siloam, dan RS Bali Royal (BROS). Rumah Sakit Swasta tersebut menerapkan SIMRS mencakup beberapa proses di unit rumah sakit antara lain sistem informasi administrasi, keuangan, sumber daya manusia, logistik, farmasi, radiologi dan juga sistem informasi rekam medis, sehingga perlu dilakukan penelitian terkait dengan keberhasilan dari SIMRS selama pandemi Covid-19 terhadap kualitas pelayanan di Rumah Sakit Swasta di Bali.

\section{METODE PENELITIAN}

Penelitian ini dilakukan di Rumah Sakit Swasta di Bali khususnya Denpasar dan Badung yang telah memiliki dan menerapkan Sistem Informasi Manajemen Rumah Sakit (SIMRS). Rumah Sakit Swasta yang dipilih adalah RSU Kasih Ibu Denpasar, RSU Surya Husadha, RSU Prima Medika, RSU Siloam, dan RS Bali Royal (BROS). Desain dari penelitian ini adalah kuantitatif untuk memotret keberhasilan SIMRS terhadap kualitas pelayanan selama Pandemi Covid-19 di RS Swasta di Bali. Populasi penelitian ini adalah semua operator di RS Swasta di Bali yang menggunakan SIMRS. Penentuan ukuran sampel menggunakan rumus Purba (2006) dengan sampel 100 responden, dikarenakan lokasi penelitian di 5 tempat berbeda yakni : RSU Kasih Ibu Denpasar, RSU Surya Husadha, RSU Prima Medika, RSU Siloam, dan RS Bali Royal (BROS), sehingga diambil sampel 20 responden pada masing-masing Rumah Sakit.

Variabel yang diteliti yaitu Kualitas SIMRS yang meliputi Safety Quality (X1), System Quality (X2), Information Quality (X3), Service Quality (X4) dan Kualitas Pelayanan Kesehatan (Y). Data penelitian diperoleh dengan menyebarkan kuisioner berupa google form ke pengguna SIMRS di RS Swasta di Bali. Teknik analisis data yang digunakan pada penelitian ini adalah dengan metode SEM (Structural Equation Model) menggunakan software SmartPLS 3.3 meliputi uji measurement model dan uji structural model (Ferdinand, 2016).

\section{HASIL DAN PEMBAHASAN}

Penelitian ini dilakukan dengan menyebarkan kuisioner pengguna SIMRS di RS Swasta di Bali sebanyak 100 responden dengan karakteristik responden yang berpartisipasi dari RSU Kasih Ibu Denpasar, RSU Surya Husadha, RSU Prima Medika, RSU Siloam, dan RS Bali Royal (BROS).

Tabel 1.

Karakteristik Responden

\begin{tabular}{llcc}
\hline No & Kriteria & Jumlah (n) & Persentase \\
\hline \multirow{2}{*}{1} & Umur & 2 & \\
\cline { 2 - 4 } & $<25$ Tahun & 52 & $2 \%$ \\
\cline { 2 - 4 } & 25-30 Tahun & 39 & $52 \%$ \\
\cline { 2 - 4 } & $31-40$ Tahun & 7 & $39 \%$ \\
\cline { 2 - 4 } & $>40$ Tahun & 100 & $100 \%$ \\
\hline \multirow{2}{*}{2} & Total Responden & & $34 \%$ \\
\cline { 2 - 4 } & Jenis Kelamin & 34 & \\
\hline
\end{tabular}

Sumber: Data diolah, 2021

Bersambung,

Memotret Keberhasilan SIMRS Terhadap Kualitas Pelayanan Selama Pandemi Covid-19 di Rumah Sakit Swasta di Bali, 
Lanjutan,

Tabel 1.

Karakteristik Responden

\begin{tabular}{|c|c|c|c|}
\hline No & Kriteria & Jumlah (n) & Persentase \\
\hline & Perempuan & 66 & $66 \%$ \\
\hline & Total Responden & 100 & $100 \%$ \\
\hline \multirow[t]{12}{*}{3} & Unit Kerja & & \\
\hline & Keperawatan & 36 & $36 \%$ \\
\hline & Laboratorium & 4 & $4 \%$ \\
\hline & UGD/IGD & 12 & $12 \%$ \\
\hline & Radiologi & 6 & $6 \%$ \\
\hline & Administrasi & 3 & $3 \%$ \\
\hline & Farmasi & 5 & $5 \%$ \\
\hline & Teknisi & 3 & $3 \%$ \\
\hline & ICU & 14 & $14 \%$ \\
\hline & Manajemen & 15 & $15 \%$ \\
\hline & Lainnya & 2 & $2 \%$ \\
\hline & Total Responden & 100 & $100 \%$ \\
\hline \multirow[t]{4}{*}{4} & Lama Bekerja & & \\
\hline & $<3$ tahun & 11 & $11 \%$ \\
\hline & $>3$ tahun & 89 & $89 \%$ \\
\hline & Total Responden & 100 & $100 \%$ \\
\hline \multirow[t]{6}{*}{5} & Pendidikan & & \\
\hline & D1/D2 & 5 & 5 \\
\hline & D3 & 34 & 34 \\
\hline & D4/S1/Profesi & 59 & 59 \\
\hline & S2 & 2 & 2 \\
\hline & Total Responden & 100 & $100 \%$ \\
\hline
\end{tabular}

Sumber: Data Primer diolah, 2021

Dari data Tabel 2 dapat dinyatakan bahwa karakteristik responden berdasarkan umur didominasi dengan rentang 25-30 tahun, dengan jenis kelamin dapat dilihat perempuan lebih mendominasi sebanyak 66\% dan laki-laki sebanyak 44\%. Berdasarkan unit kerja didominasi oleh unit keperawatan dimana masa kerja responden mayoritas lebih dari 3 tahun (89\%). Berdasarkan jenjang pendidikan dapat dilihat bahwa yang paling dominan D4/S1/Profesi (59\%). Pengujian validitas penelitian ini dilakukan dengan menghitung Pearson Correlation $>0,30$ yang merupakan sebagai nilai pembanding minimal untuk mendapatkan korelasi yang valid (Sugiyono, 2017).

Tabel 2.

Hasil Uji Validitas

\begin{tabular}{ccccc}
\hline \multirow{2}{*}{ Variabel } & Indikator & $\begin{array}{c}\text { Correlation } \\
\text { Item }\end{array}$ & Nilai Kritis & Keterangan \\
\hline \multirow{4}{*}{ Safety Quality } & $\mathrm{X} 1.1$ & 0,774 & 0,30 & Valid \\
\cline { 2 - 5 } & $\mathrm{X} 1.2$ & 0,85 & 0,30 & Valid \\
\cline { 2 - 5 } & $\mathrm{X} 1.3$ & 0,857 & 0,30 & Valid \\
\cline { 2 - 5 } & $\mathrm{X} 1.4$ & 0,898 & 0,30 & Valid \\
\hline \multirow{3}{*}{ System Quality } & $\mathrm{X} 1.5$ & 0,84 & 0,30 & Valid \\
\cline { 2 - 5 } & $\mathrm{X} 2.1$ & 0,871 & 0,30 & Valid \\
\cline { 2 - 5 } & $\mathrm{X} 2.2$ & 0,877 & 0,30 & Valid \\
\cline { 2 - 5 } & $\mathrm{X} 2.3$ & 0,896 & 0,30 & Valid \\
\hline
\end{tabular}

Sumber : Data diolah, 2021

Bersambung,

Memotret Keberhasilan SIMRS Terhadap Kualitas Pelayanan Selama Pandemi Covid-19 di Rumah Sakit Swasta di Bali, 
Lanjutan,

Tabel 2.

Hasil Uji Validitas

\begin{tabular}{|c|c|c|c|c|}
\hline Variabel & Indikator & $\begin{array}{c}\text { Correlation } \\
\text { Item }\end{array}$ & Nilai Kritis & Keterangan \\
\hline & $\mathrm{X} 2.5$ & 0,745 & 0,30 & Valid \\
\hline \multirow{5}{*}{ Information Quality } & $\mathrm{X} 3.1$ & 0,839 & 0,30 & Valid \\
\hline & $\mathrm{X} 3.2$ & 0,862 & 0,30 & Valid \\
\hline & X3.3 & 0,862 & 0,30 & Valid \\
\hline & X3.4 & 0,863 & 0,30 & Valid \\
\hline & $\mathrm{X} 3.5$ & 0,864 & 0,30 & Valid \\
\hline \multirow{5}{*}{ Service Quality } & $\mathrm{X} 4.1$ & 0,846 & 0,30 & Valid \\
\hline & $\mathrm{X} 4.2$ & 0,885 & 0,30 & Valid \\
\hline & $\mathrm{X} 4.3$ & 0,863 & 0,30 & Valid \\
\hline & $\mathrm{X} 4.4$ & 0,855 & 0,30 & Valid \\
\hline & $\mathrm{X} 4.5$ & 0,854 & 0,30 & Valid \\
\hline \multirow{5}{*}{ Kualitas Pelayanan } & Y1.1 & 0,828 & 0,30 & Valid \\
\hline & $\mathrm{Y} 1.2$ & 0,755 & 0,30 & Valid \\
\hline & Y1.3 & 0,775 & 0,30 & Valid \\
\hline & Y1.4 & 0,813 & 0,30 & Valid \\
\hline & Y1.5 & 0,795 & 0,30 & Valid \\
\hline
\end{tabular}

Sumber: Data Primer diolah, 2021

Berdasarkan Tabel 2 dapat diketahui bahwa instrumen-instrumen pada setiap variabel dalam penelitian ini adalah valid dan dapat dipakai untuk menguji hipotesis penelitian, karena nilai pada setiap instrumen memiliki nilai di atas 0,30.

Uji reliabilitas dilakukan dengan tujuan instrumen yang diukur dapat dipercaya dan diandalkan. Suatu variabel dikatakan reliabel jika memiliki nilai Cronbach Alpha (a) lebih besar dari 0,60 (Ghozali, 2018).

Tabel 3.

Uji Reliabilitas

\begin{tabular}{lccc}
\hline No & Variabel & Cronbach's Alpha & Keterangan \\
\hline 1 & Safety Quality & 0,899 & Reliabel \\
\hline 2 & System Quality & 0,906 & Reliabel \\
\hline 3 & Information Quality & 0,910 & Reliabel \\
\hline 4 & Service Quality & 0,912 & Reliabel \\
\hline 5 & Kualitas Pelayanan & 0,853 & Reliabel
\end{tabular}

Sumber: Data Primer diolah, 2021

Berdasarkan Tabel 3 dapat diketahui bahwa seluruh instrument di atas reliabel karena nilai $\mathrm{r}$ alpha hitung masing-masing instrumen tersebut lebih besar dari 0,60. Hasil evaluasi model struktural dari variable eksogen yaitu Kualitas SIMRS yang meliputi Safety Quality (X1), System Quality (X2), Information Quality (X3), Service Quality (X4) dan variabel endogen yaitu Kualitas Pelayanan Kesehatan (Y) didapatkan hasil koefisien determinasi $\left(\mathrm{R}^{2}\right)$ dari variabel endogen dapat disajikan dalam Tabel 4.

Memotret Keberhasilan SIMRS Terhadap Kualitas Pelayanan Selama Pandemi Covid-19 di Rumah Sakit Swasta 
Tabel 4.

Nilai $R$-square Variabel Endogen

\begin{tabular}{llll}
\hline $\begin{array}{l}\text { Model } \\
\text { Struktural }\end{array}$ & Variabel Dependen & $\boldsymbol{R}$-square & $\begin{array}{l}\text { Adjusted } \\
\boldsymbol{R} \text {-square }\end{array}$ \\
\hline 1 & Kualitas Pelayanan & 0,793 & 0,784 \\
\hline Sumber: Data Primer diolah, 2021 & &
\end{tabular}

Tabel 4 menunjukkan bahwa nilai $\mathrm{R}^{2}$ Kualias Pelayanan sebesar 0,793 , berdasarkan kriteria (Ghozali, 2018), maka model tersebut termasuk kriteria model kuat, maknanya adalah Kualitas Pelayanan mampu menjelaskan model sebesar $79,3 \%$ persen, sisanya $20,7 \%$ persen dijelaskan oleh variasi variabel lain diluar model yang dianalisis.

Penelitian ini menggunakan pendekatan analisis Partial Least Square (PLS) untuk melakukan uji terhadap hipotesis penelitian. Hasil analisis model empiris penelitian dengan menggunakan analisis Partial Least Square (PLS) ini dapat dilihat dalam Gambar 1.

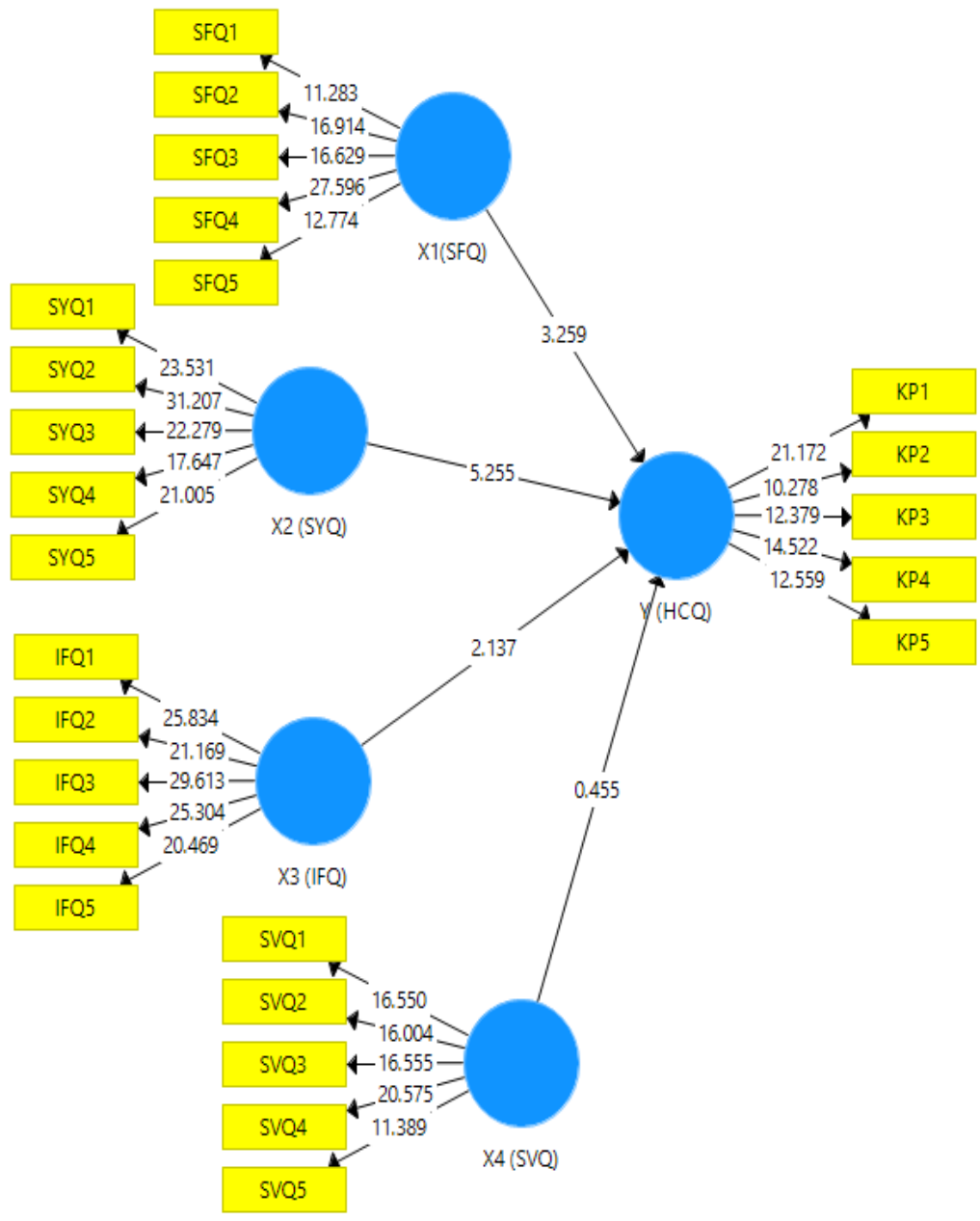

Sumber: Data diolah, 2021

Gambar 1.

Boothstarpping Variabel Penelitian

Memotret Keberhasilan SIMRS Terhadap Kualitas Pelayanan Selama Pandemi Covid-19 di Rumah Sakit Swasta 
Tabel 4.

Hasil Analisis Jalur

\begin{tabular}{llrrrrr}
\hline & $\begin{array}{l}\text { Original } \\
\text { Sample (O) }\end{array}$ & $\begin{array}{l}\text { Sample Mean } \\
(\mathbf{M})\end{array}$ & $\begin{array}{l}\text { Standard } \\
\text { Deviation } \\
\text { (STDEV) }\end{array}$ & $\begin{array}{l}\text { T Statistics } \\
(\mid \mathbf{O} / \text { STDEV })\end{array}$ & P values \\
\hline X1(SFQ) -> Y (HCQ) & 0,207 & 0,196 & 0,066 & 3,121 & 0,002 \\
X2 (SYQ) -> Y (HCQ) & 0,526 & 0,538 & 0,106 & 4,975 & 0,000 \\
X3 (IFQ) -> Y (HCQ) & 0,210 & 0,213 & 0,100 & 2,096 & 0,037 \\
X4 (SVQ) -> Y (HCQ) & 0,031 & 0,023 & 0,071 & 0,439 & 0,661 \\
\hline
\end{tabular}

Sumber: Data Primer diolah, 2021

Hasil pengujian hipotesis menunjukkan bahwa Safety Quality dari SIMRS terbukti berpengaruh positif dan signifikan terhadap kualitas pelayanan Kesehatan selama pandemi Covid-19 di RS Swasta di Bali. Hal ini ditunjukkan oleh koefisien jalur yang bernilai positif sebesar 0,207 dengan nilai t-statistik sebesar 3,121 (t-statistic > 1,96) dan $p$ value sebesar 0,002 ( $p$ value $<0,05$ ) yang berarti bahwa hipotesis pertama dalam penelitian ini dapat diterima secara empiris. Hasil yang diperoleh dapat dimaknai bahwa semakin baik Safety Quality, maka kualitas pelayanan kesehatan selama pandemi Covid-19 di RS Swasta di Bali semakin meningkat. Temuan penelitian ini memberikan gambaran bahwa Safety Quality dengan indikator kelengkaan data, kehilangan data, kebenaran dan akurasi, proteksi data dan privasi pasien dapat meningkatkan kualitas pelayanan Kesehatan selama pandemi covid-19 di RS Swasta di Bali.

Hasil penelitian ini diperkuat hasil penelitian Falsteen (2016) dimana keamanan dapat didefinisikan sebagai tingkat perlindungan terhadap aktivitas kriminal, bahaya, kerusakan,dan / atau kehilangan. Kerentanan sumber daya informasi adalah kemungkinan bahwa sistem akan dirugikan oleh berbagai ancaman. Hasil penelitian dari Falsteen (2016) dengan menggunakan 258 sampel Rumah Sakit Gaza, Eropa menunjukkan hasil ada korelasi yang signfikan $(p$ value $<0,05)$ antara keamanan sistem informasi rumah sakit dengan pelayanan di rumah sakit di Gaza, Eropa.

Hasil penelitian Kinasih \& Albari (2012) dengan subyek penelitian melibatkan sampel sebanyak 96 orang melalui teknik convenience sampling menunjukkan adanya pengaruh positif persepsi keamanan dan privasi terhadap kepuasan konsumen online. Kedua variabel tersebut bersamasama dengan kepuasan juga bisa berpengaruh positif terhadap kepercayaan konsumen. Penelitian dari Hendyca Putra \& Siswanto (2016) menyatakan keamanan pada sistem informasi klinik memberikan pengaruh pada kepuasan pengguna. Maka dari itu safety quality (kualitas keamanan) dari SIMRS akan meningkatkan kualitas pelayanan kesehatan selama pandemi covid-19 di RS Swasta di Bali

Hasil pengujian hipotesis menunjukkan bahwa System Quality dari SIMRS terbukti berpengaruh positif dan signifikan terhadap kualitas pelayanan kesehatan selama pandemi covid-19 di RS Swasta di Bali. Hal ini ditunjukkan oleh koefisien jalur yang bernilai positif sebesar 0,526 dengan nilai t-statistik sebesar 4,975 (t-statistic > 1,96) dan $p$ value sebesar 0,000 ( $p$ value $<0,05$ ) yang berarti bahwa hipotesis kedua dalam penelitian ini dapat diterima secara empiris. Hasil yang diperoleh dapat dimaknai bahwa semakin baik System Quality, maka kualitas pelayanan kesehatan selama pandemi covid-19 di RS Swasta di Bali semakin meningkat. Temuan penelitian ini memberikan gambaran bahwa System Quality dengan kemudahan pengguna, kemudahan dipelajari, kecepatan akses, keandalan system dan fleksibelitas dapat meningkatkan kualitas pelayanan Kesehatan selama pandemi covid-19 di RS Swasta di Bali

Hasil penelitian ini didukung oleh hasil penelitian Amalia \& Pratomo (2016) menunjukkan hasil penelitian yang serupa bahwa System Quality memiliki dampak yang signifikan terhadap penggunaan sistem. Kualitas sistem (System Quality) dan kualitas informasi (Information Quality)

Memotret Keberhasilan SIMRS Terhadap Kualitas Pelayanan Selama Pandemi Covid-19 di Rumah Sakit Swasta di Bali, 
yang diterapkan dirumah sakit RS PKU Muhammadiyah Sruweng memiliki hubungan yang searah (positif) dan signifikan terhadap penggunaan sistem (System Use) dan kepuasaan pengguna (User Satisfaction) yaitu manusia sebagai pengguna akhir sistem. Sehingga untuk peningkatan dan perbaikan kualitas teknologi (Technology) yaitu kualitas system (Bayu \& Izzati, 2013).

Hasil penelitian dari Falsteen (2016) dengan menggunakan 258 sampel Rumah Sakit Gaza, Eropa menunjukkan hasil ada korelasi yang signifikan $(p$ value $<0,05)$ antara kualitas sistem informasi rumah sakit dengan pelayanan di rumah sakit di Gaza, Eropa. Hasil penelitian serupa lainnya juga ditunjukkan oleh Hendyca Putra dan Siswanto (2016), kualitas sistem memiliki pengaruh yang positif dan signifikan terhadap kepuasan pengguna pada sistem informasi manajemen rumah sakit kalisat. Hal ini dibuktikan dengan T-hitung >T-tabel $(-1,627>-1,187)$. Penelitian Wicaksono, dkk., (2016) menjelaskan pengaruh positif kualitas sistem terhadap minat memakai ini dapat disebabkan karena pengguna akan merasa pekerjaannya lebih mudah dan lebih cepat terselesaikan dengan ingin menggunakan sistem infomasi yang kualitas sistemnya baik. Pengguna akan merasa nyaman menggunakan sistem infomasi dalam pekerjaannya karena sistem didukung dengan kualitas yang baik. Maka dari itu system quality fet dari SIMRS akan meningkatkan kualitas pelayanan kesehatan selama pandemi covid-19 di RS Swasta di Bali.

Hasil pengujian hipotesis menunjukkan bahwa Information Quality dari SIMRS terbukti berpengaruh positif dan signifikan terhadap kualitas pelayanan kesehatan selama pandemi covid-19 di RS Swasta di Bali. Hal ini ditunjukkan oleh koefisien jalur yang bernilai positif sebesar 0,210 dengan nilai t-statistik sebesar 2,096 (t-statistic > 1,96) dengan $p$ value sebesar 0,037 ( $p$ value $<0,05$ ), yang berarti bahwa hipotesis ketiga dalam penelitian ini dapat diterima secara empiris. Hasil yang diperoleh dapat dimaknai bahwa semakin baik Information Quality, maka kualitas pelayanan kesehatan selama pandemi covid-19 di RS Swasta di Bali semakin meningkat. Temuan penelitian ini memberikan gambaran bahwa Information Quality dengan indikator akurasi, kelengkapan, bentuk system, ketepatan waktu dan relevansi dapat meningkatkan kualitas pelayanan Kesehatan selama pandemi covid-19 di RS Swasta di Bali. Hasil penelitian ini diperkuat oleh hasil penelitian Negara \& Pratomo (2019) menunjukkan bahwa kualitas informasi tidak berpengaruh signifikan terhadap kepuasaan penguna. Kualitas informasi berpengaruh positif pada penggunaan mengindikasikan bahwa kualitas informasi yang baik akan mempengaruhi pengguna dalam keberlanjutan penggunaan sistem $e$-filling (Kirana, 2010).

Penelitian Hendyca Putra \& Siswanto (2016) menunjukkan bahwa kualitas informasi memiliki pengaruh terhadap kepuasan pengguna. Hal ini dibuktikan dengan lebih besarnya T-hitung dibandingkan dengan pada tabel $(-2,341>-1,187)$. Pengukur-pengukur pada kualitas informasi seperti, akurasi informasi, kelengkapan informasi yang disajikan, bentuk output dari informasi yang disajikan, ketepatan waktu, dan relevansi informasi yang disajikan pada sistem informasi klinik memberikan pengaruh pada kepuasan pengguna. Penelitian Wicaksono, dkk., (2016) menunjukkan pengaruh positif kualitas informasi terhadap minat memakai dapat disebabkan karena pengguna akan menggunakan kembali sistem informasi yang diterapkan jika kualitas infomasi yang dihasilkan oleh sistem membantunya dalam menyelesaikan pekerjaan. Pengaruh positif kualitas infomasi terhadap kepuasan pengguna dapat disebabkan karena pengguna puas dengan menggunakan sistem infomasi, pekerjaan yang berkaitan dengan pencatatan data maupun pelaporan data dalam sistem SIM-RS dapat berjalan dengan baik menghasilkan kualitas infomasi. Hasil penelitian dari Falsteen, dkk., (2016) dengan menggunakan 258 sampel Rumah Sakit Gaza, Eropa menunjukkan hasil ada korelasi yang signfikan ( $p$ value < 0,05) antara information Quality sistem informasi rumah sakit dengan pelayanan di rumah sakit di Gaza, Eropa. Maka dari itu information quality (kualitas informasi) dari SIMRS akan meningkatkan kualitas pelayanan kesehatan selama pandemi covid-19 di RS Swasta di Bali.

Memotret Keberhasilan SIMRS Terhadap Kualitas Pelayanan Selama Pandemi Covid-19 di Rumah Sakit Swasta 
Hasil pengujian hipotesis menunjukkan bahwa Service Quality dari SIMRS tidak terbukti berpengaruh positif dan signifikan terhadap kualitas pelayanan kesehatan selama pandemi covid-19 di RS Swasta di Bali. Hal ini ditunjukkan oleh koefisien jalur yang bernilai positif sebesar 0,031 dengan nilai t-statistik sebesar 0,439 (t-statistic < 1,96) dengan $p$ value sebesar 0,661 ( $p$ value $>0,05$ ) yang berarti bahwa hipotesis keempat dalam penelitian ini tidak dapat diterima secara empiris. Hasil yang diperoleh dapat dimaknai bahwa Service Quality dari SIMRS tidak berpengaruh secara signifikan terhadap kualitas pelayanan Kesehatan selama pandemi covid-19 di RS Swasta di Bali.

Hasil penelitian ini diperkuat oleh penelitian Bayu \& Izzati (2013), dimana service quality tidak memberikan pengaruh yang signifikan terhadap kepuasan pengguna. hal ini disebabkan karena sistem sering error terutama pada jam-jam pelayanan yang sibuk dan mengakibatkan informasi yang diharapkan lambat diperoleh, seingga mengurangi kepuasan pengguna. Pihak vendor harus memantau kemampuan sistem dalam memproses data sehingga dapat diketahui puncak jumlah data atau jumlah pengguna yang mengakses sistem yang mengakibatkan sistem menjadi lambat. Perbaikan sistem jaringan komputer seperti pemisahan backbone SIMRS dengan jaringan intranet rumah sakit. Layanan vendor dibagian tertentu dinilai kurang cepat, karena keterbatasan personil vendor. Hal ini dapat diatasi dengan memberdayakan personil EDP, supaya personil EDP dapat membatu, maka EDP perlu dilibatkan dalam proses perawatan sistem agar mengetahui dokumentasi SIMRS.

Hasil penelitian Puspitasari \& Nugroho (2018) menunjukkan bahwa faktor service quality tidak berpengaruh terhadap net benefit yang meliputi efisiensi pekerjaan, efektifitas, mengurangi tingkat kesalahan, biaya operasional. Ketidakpuasan pengguna disebabkan karena layanan vendor yang kurang cepat responnya saat dibutuhkan, tidak tersedianya helpdesk, vendor belum memberikan jaminan kualitas dan layanan terhadap penggunaan SIMRS serta belum mampu menyelesaikan permasalahan yang mungkin timbul dalam penggunaan SIMRS. Komunikasi yang baik akan menghasilkan informasi-informasi yang diperlukan untuk analisa kebutuhan manajemen rumah sakit sehingga penerapan SIMRS bisa bermanfaat bagi semua pihak. Maka dari itu Service Quality dari SIMRS tidak berpengaruh signifikan terhadap kualitas pelayanan kesehatan selama pandemi covid-19 di RS Swasta di Bali.

Hasil pengujian hipotesis menunjukkan bahwa Safety Quality memiliki koefisien path sebesar 0,207; System Quality memiliki koefisien path sebesar 0,526; Information Quality memiliki koefisien path sebesar 0,210 dan Service Quality memiliki koefisien path sebesar 0,031. Maka Faktor yang paling dominan dari SIMRS yang mempengaruhi kualitas pelayanan Kesehatan selama pandemi covid-19 di RS Swasta di Bali adalah System Quality yang memiliki koefisien path terbesar yaitu 0,526 dibandingkan dengan koefisien path System Quality, Information Quality, dan Service Quality.

Hasil penelitian ini diperkuat hasil penelitian Puspitasari \& Nugroho (2018) yang menyatakan kemudahan teknologi merupakan hal yang mempengaruhi frekuensi penggunaan sistem. Kemudahan penggunaan juga dipengaruhi oleh kemudahan untuk dipelajari dan kemanfaatan dipengaruhi oleh kemudahan penggunaan. Berdasarkan hasil observasi terhadap responden kemudahan sistem mempengaruhi kepuasan penggunanya dalam membantu pekerjaan mereka mengolah data dan informasi. Kemudahan teknologi merupakan hal yang mempengaruhi frekuensi penggunaan sistem. Sementara kemudahan dan kemanfaatan akan mempengaruhi penerimaan sistem oleh penggunanya. Sistem yang diterima akan memberikan kepuasan bagi penggunanya (Anis \& Lutfan, 2018).

Penelitian lainnya juga menyatakan hal serupa bahwa pengaruh positif kualitas sistem terhadap minat memakai ini dapat disebabkan karena pengguna akan merasa pekerjaannya lebih mudah dan lebih cepat terselesaikan dengan ingin menggunakan sistem infomasi yang kualitas sistemnya baik. Adanya pengaruh positif kualitas system terhadap kepuasan pengguna dapat

Memotret Keberhasilan SIMRS Terhadap Kualitas Pelayanan Selama Pandemi Covid-19 di Rumah Sakit Swasta di Bali, 
disebabkan karena pengguna akan merasakan sebuah kepuasan jika sistem informasi yang digunakan dapat memenuhi kebutuhannya. Pekerjaan akan menjadi lebih mudah dan lebih cepat terselesaikan (Wicaksono dkk., 2016).

\section{SIMPULAN DAN SARAN}

Berdasarkan hasil penelitian dapat ditarik kesimpulan bahwa Safety Quality, System Quality, dan Information Quality dari SIMRS terbukti berpengaruh positif dan signifikan terhadap kualitas pelayanan Kesehatan selama pandemi covid-19 di RS Swasta di Bali (t-statistic > 1,96 dan $p$ value < 0,05). Service Quality dari SIMRS tidak terbukti berpengaruh positif dan signifikan terhadap kualitas pelayanan kesehatan selama pandemi covid-19 di RS Swasta di Bali (t-statistic < 1,96 dan $p$ value > 0,05). System Quality dari SIMRS merupakan faktor yang paling dominan yang mempengaruhi kualitas pelayanan Kesehatan yang memiliki koefisien path 0,526. Kualitas dari SIMRS sangat membantu manajemen dan user dalam melakukan pelayanan Kesehatan, kualitas SIMRS yang berjalan dengan baik maka pihak manajemen atau user akan dengan cepat dan mudah mengakses informasi yang dibutuhkan untuk pelayanan Kesehatan di Rumah Sakit.

Saran yang penulis untuk manajemen Rumah Sakit khususnya RS Swasta di Bali perlu dilakukan peningkatan kualitas dari SIMRS (Safety Quality, System Quality, dan Information Quality) yang berdampak langsung pada kualitas pelayanan Kesehatan selama pandemi covid-19, kualitas SIMRS yang baik dapat memberikan kemudahan serta efisien dalam pelayanan Kesehatan. Perlu dilakukan pelatihan secara berkala untuk operator dan update system/software dari SIMRS yang disesuaikan dengan kebutuhan dan kemampuan RS masing-masing. Selain itu, peneliti mendatang dapat memodifikasi model penelitian dengan menambahkan atau mengembangkan indikator maupun variabel lain seperti kualitas jaringan, kualitas SDM/operator, kualitas hardware dan sebagainya yang berkaitan dengan SIMRS.

\section{REFERENSI}

Aji, M. B. (2017). Evaluasi Penerapan Sistem Informasi Menejemen Rumah Sakit RSIA Bhakti Persada Magetan Menggunakan TAM Mochamat Bayu Aji Akbid Muhammadiyah Madiun. Duta.Com, 12(2), 3156.

Amalia, S. M., \& Pratomo, D. (2016). Perceived Usefulness Terhadap Kepuasan Pengguna Sistem Informasi Akuntansi ( Studi Pada Pengguna Sistem Informasi Akuntansi Di Rumah Sakit Mata Cicendo Bandung ) the Influence of Information System Quality, Information Quality, and Perceived Usefulness. EProceeding of Management, 3(1), 1516-1522.

Anis, K., \& Lutfan, L. (2018). Evaluasi Sistem Informasi Manajemen Rumah Sakit Rajawali Citra Yogyakarta Menggunakan Model Human Organization Technology Fit (HOT-Fit). Journal of Information Systems for Public Health, 3(2), 19-26. https://doi.org/10.1128/AAC.39.8.1752

Bayu, A., \& Izzati, S. (2013). Evaluasi Faktor-Faktor Kesuksesan Implementasi Sistem Informasi manajemen Rumah Sakit di PKU Muhammadiyah Sruweng dengan Menggunakan Metode. Seminar Nasional Informatika Medis, November, 78-86.

Dinas Kesehatan Provinsi Bali. (2017). Profil Kesehatan Provinsi Bali Tahun 2016. Bali: Dinas Kesehatan Porvinsi Bali

Erlirianto, L. M., Ali, A. H. N., \& Herdiyanti, A. (2015). The Implementation of the Human, Organization, and Technology-Fit (HOT-Fit) Framework to Evaluate the Electronic Medical Record (EMR) System in a Hospital. Procedia Computer Science, 72(2015), 580-587. https://doi.org/10.1016/j.procs.2015.12.166

Falsteen, N. M. (2016). the Impact of Hospital Information System Quality on the Health Care Quality: a Case Study on European Gaza Hospital. Iugspace.Iugaza.Edu.Ps. https://iugspace.iugaza.edu.ps/bitstream/handle/20.500.12358/17574/file_1.pdf?sequence=1

Ferdinand, P. D. A. (2016). Metode Penelitian Manajemen: Pedoman Penelitian untuk Skripsi, Tesis dan

Memotret Keberhasilan SIMRS Terhadap Kualitas Pelayanan Selama Pandemi Covid-19 di Rumah Sakit Swasta di Bali, 
Disertasi Ilmu Manajemen. In BP Undip 2. https://doi.org/10.4304/jcp.8.2.326-333

Gunawan, I. (2013). Evaluasi Sistem Informasi Manajemen Rumah Sakit ( SIMRS) RSUD Brebes Dalam Kesiapan Penerapan Sistem Informasi Rumah Sakit ( SIRS ) Online Kemenkes Ri Tahun 2013. 1-15.

Handayani, P. W., Hidayanto, A. N., Pinem, A. A., Hapsari, I. C., Sandhyaduhita, P. I., \& Budi, I. (2017). Acceptance model of a Hospital Information System. International Journal of Medical Informatics, 99, 11-28. https://doi.org/10.1016/j.ijmedinf.2016.12.004

Hariningsih, E. (2014). Kajian Teori Model Penelitian Untuk Menilai Kesuksesan Dan Evaluasi Sistem Informasi Rumah Sakit. Jbma, 11(1), 14-23. http://jurnal.amaypk.ac.id/index.php/jbma/article/view/26/25

Hendyca Putra, D. S., \& Siswanto, M. (2016). Pengaruh Kualitas Sistem, Kualitas Informasi Dan Kualitas Layanan Terhadap Kepuasan Pengguna Sistem Informasi Manajemen Rumah Sakit Daerah Kalisat Kabupaten Jember. Jurnal Ilmiah Inovasi, 16(2), 98-101. https://doi.org/10.25047/jii.v16i2.291

Kementerian Kesehatan Republik Indonesia. (2020). Pedoman Kesiapsiagaan Menghadapi Coronavirus Disease (COVID-19). Direkorat Jenderal Pencegahan Dan Pengendalian Penyakit, 1-88.

Kirana, G. G. (2010). Analisis Perilaku Penerimaan Wajib Pajak Terhadap Penggunaan E-Filling. In Skripsi. Fakultas Ekonomi Universitas Diponegoro. Semarang. Universitas Diponegoro.

Komisi Akreditasi Rumah Sakit. (2018). Standar Nasional Akreditasi Rumah Sakit (SNARS) Edisi 1 (Edisi 1). KARS.

Lam, N., Muravez, S. N., \& Boyce, R. W. (2015). A comparison of the Indian Health Service counseling technique with traditional, lecture-style counseling. In Journal of the American Pharmacists Association 55(5), 503-510. https://doi.org/10.1331/JAPhA.2015.14093

Lestari, W. H. (2014). Evaluasi Sistem Informasi Manajemen Rumah Sakit di Rumah Sakit Rajawali Citra Bantul Yogyakarta Tahun 2014, 11(44). http://eprints.dinus.ac.id/6634/

Mardiyoko, I., \& Hartini, W. M. (2018). Sistem Informasi Manajemen Rumah Sakit Menggunakan Model End User Computing Satisfaction Di Rsud Panembahan Senopati Bantul. 3(11), 30-42.

Negara, V. P., \& Pratomo, D. (2019). Pengaruh Kualitas Sistem, Kualitas Informasi Dan Kualitas Layanan Her Registrasi Igracias Terhadap Kepuasan Pengguna. JAF- Journal of Accounting and Finance, 1(01), 33. https://doi.org/10.25124/jaf.v1i01.903

Nugroho. (2013). Penggunaan Sistem Informasi Manajemen Rumah. Seminar Nasional Sistem Informasi Indonesia, 2-4.

Odelia, EM. (2018). Pengembangan Kapasitas Organisasi Melalui Penerapan Sistem Informasi Manajemen Rumah Sakit (SIMRS) Untuk Meningkatkan Mutu Pelayanan Kesehatan di RSUD dr. Mohamad Soewandhie Surabaya. Kebijakan Dan Manajemen Publik, 6(4), 1-8. http://journal.unair.ac.id/downloadfullpapers-kmp943047242efull.pdf

Parasuraman, A. A., Zeithaml, V. A., \& Berry, L. L. (2011). Refinement and reassessment of the SER VQUAL instrument. Journal of Retailing, 67(4), 420-450.

Peraturan Menteri Kesehatan RI No 1691/Menkes/PER/VIII/2011, 2 PMK RI $297 \quad$ (2011). https://doi.org/10.5296/jpag.v8i3.13638

Purba, R. (2006). Measuring Customer Perception Through Factor Analysis. The Asian Manager

Puspitasari, E. R., \& Nugroho, E. (2018). Evaluasi implementasi sistem informasi manajemen rumah sakit di rsud kabupaten temanggung dengan menggunakan metode hot-fit. Journal of Information Systems for Public ..., 3(3), 63-77. https://journal.ugm.ac.id/jisph/article/view/37562

Saputra, andika bayu. (2013). Evaluasi faktor-faktor kesuksesan implementasi SIMRS di RS PKU Muhammadiyah Sruweng dengan Menggunakan Metode Hot-Fit. November, 78-86.

Setyaningrum, A. (2015). Analisis Sistem Informasi Registrasi Pasien dengan Metode Pieces di Rumah Sakit Mulia Hati Wonogiri [Universitas Muhammadiyah Surakarta]. http://eprints.ums.ac.id

Susilo, A., Rumende, C. M., Pitoyo, C. W., Santoso, W. D., Yulianti, M., Herikurniawan, H., Sinto, R., Singh, G., Nainggolan, L., Nelwan, E. J., Chen, L. K., Widhani, A., Wijaya, E., Wicaksana, B., Maksum, M., Annisa, F., Jasirwan, C. O. M., \& Yunihastuti, E. (2020). Coronavirus Disease 2019: Tinjauan Literatur Terkini. Jurnal Penyakit Dalam Indonesia, 7(1), 45. https://doi.org/10.7454/jpdi.v7i1.415

United Nations. (2020). United Nations Sustainable Development Knowledge Platform. https://sustainabledevelopment.un.org/

Wicaksono, H. N., Utami, S., \& Witcahyo, E. (2016). Analisis Kesuksesan Sistem Informasi Manajemen Menggunakan Pendekatan Updated D \& M Is Success Model Di Rumah Sakit Umum Kaliwates Jember (The Successed Analysis of Management Information System by Updated D \& M IS Success Model Approached at The Kaliwat). Repository.Unej.Ac.Id. https://repository.unej.ac.id/handle/123456789/83609

Memotret Keberhasilan SIMRS Terhadap Kualitas Pelayanan Selama Pandemi Covid-19 di Rumah Sakit Swasta di Bali, 